\title{
CONSTRUINDO VÍDEOS: autoria e interação favorecidas no Laboratório de Informática de escola pública
}

Carla Inez L. de F. Anele, EMEF V. Martim Aranha, SMED - carlainlima@ gmail.com Mára Lúcia Carneiro, Instituto de Psicologia, UFRGS - mara.carneiro@ufrgs.br

Resumo: Neste artigo procuramos analisar uma proposta de trabalho que valoriza a autoria e o conhecimento dos estudantes concluintes do ensino fundamental sobre as tecnologias utilizadas no Laboratório de Informática (LI) de uma escola pública. Nesse artigo analisamos o processo dialógico, a interação entre os estudantes, professores e tecnologias disponíveis no LI da escola. A experiência da construção de vídeos e as aprendizagens ocorridas em interação permitiram, como observado, novas formas de atuação docente.

Palavras-chave: Interação. Autoria. Planejamento. Tecnologias.

Abstract: In this paper we analyze a job offer that values the students graduating from elementary school authorship and knowledge about technologies used in a public school Computer Lab. In this paper we analyze the dialogical process, interaction between students, teachers and technologies available in the school Computer Lab. The building videos experience and interaction occurring learning allowed, as noted, new ways of teaching performance.

Keywords: Interaction. Authorship. Planning. Technologies.

\section{Introdução}

A proposta deste trabalho parte de observações realizadas no LI de uma escola pública localizada na zona oeste da cidade de Porto Alegre e da interação de estudantes, concluintes do Ensino Fundamental, com as tecnologias disponibilizadas naquele espaço. Procurou-se analisar como as produções e escolhas dos jovens estudantes foram acolhidas pelo grupo de professores que fez o planejamento para a utilização do espaço informatizado da escola. As expectativas, dúvidas, impressões e mudança de comportamento dos jovens, quando desafiados para a realização de um trabalho sobre temas escolhidos por eles, foram observadas durante a realização da pesquisa.

$\mathrm{Na}$ escola, geralmente, os temas, conteúdos e alguns dos valores presentes no planejamento dos professores sofre influência de seus conhecimentos e vivências pessoais. Muitas vezes, as escolhas sobre que deve ser ensinado, não são acolhidas pelos alunos, que demonstram desinteresse, pois para eles não fazem sentido, não os tocam, não os sensibilizam, tampouco despertam seu desejo em conhecer alguns destes temas, conteúdos e valores presentes no planejamento do grupo de professores.

Procurou-se fundamentar as análises a partir dos conceitos de interação e tomada de consciência como proposto pelo epistemólogo Jean Piaget (1978, 2007, 2010), bem como nos conceitos de enunciado, posição enunciativa, produção de sentido e autoria como desenvolvidos por Mikhail Bakhtin (2006).

Este trabalho pode contribuir para o entendimento de que é possível produzir novas formas para o fazer educativo acolhendo o trabalho de pesquisa e de criação dos estudantes, particularmente, aquele que é fruto de seu interesse e curiosidade. 
A flexibilidade - quando se analisa o trabalho de um educador, que não pretende "formar" um grupo de homogêneos e sim trabalhar com a diferença e o sentido - é essencial. Atualmente, entende-se que todo educador precisa de uma formação que o prepare para aceitar e compreender a diferença, que o instigue a buscar sempre e mais formas de entender a multiplicidade do humano, das culturas e, principalmente, de não se intimidar ou se amedrontar perante o inusitado.

\title{
2. As escolhas dos estudantes sobre os temas que desejam estudar podem dar um sentido maior ao planejamento dos professores e facilitar os processos de interação.
}

No terceiro ano do terceiro ciclo ( $9^{\circ}$ ano do ensino fundamental), os alunos de quatro turmas, receberam a proposta de construir um trabalho científico. Este trabalho foi chamado Trabalho de Conclusão (TC). Cada aluno deveria escolher um tema, alguma coisa que o tocou durante os seus estudos ou algo que ainda não havia aprendido, mas que teria curiosidade em saber, para desenvolver uma pesquisa utilizando a internet. Depois de realizada a pesquisa, eles apresentariam o seu trabalho para os colegas e familiares. Foi combinado que para apresentação deveriam construir um vídeo utilizando o Windows Movie Maker (WMM).

Corte Real et al. (2007), abordam uma experiência construída na interface da metodologia de Projetos de Aprendizagem (PAs) e Tecnologias Digitais, ocorrida em uma escola municipal de Porto Alegre. Esta experiência foi realizada com alunos na faixa etária entre onze e doze anos, do segundo ciclo. As autoras realizaram observações e entrevistas coletivas com os alunos para demonstrar como a informática, juntamente com a metodologia de projetos de aprendizagem interferiu e transformou a convivência de alunos na escola.

O referido trabalho contribui para trazer evidências sobre o quanto a escolha dos alunos sobre o que desejam aprender pode emocionar os sujeitos participantes dos processos de pesquisa e aprendizagem e proporcionar condutas de cooperação, entre eles, durante as interações, nos diferentes espaços de aprendizagem da escola, seja a sala de aula ou o Laboratório de Informática.

Segundo as autoras,

\begin{abstract}
A escolha de um tema de interesse individual e/ou grupal traz em si algo presente no emocionar de cada um dos presentes, ou seja, não é à toa que se escolhe trabalhar "hip hop", "pagode", "alimentação", "modelo", as escolhas têm a ver com os interesses subjetivos dos participantes de cada grupo. Nesse sentido Piaget (2001) refere à assimilação e à acomodação nas relações com a afetividade quando nos aponta que não há trabalho sem necessidade; não há ato de inteligência sem pergunta, quer dizer, sem experimentar a sensação de uma lacuna, portanto, sem desequilíbrio, sem necessidade. [...]. (CORTE REAL, et al., 2007, p.4).
\end{abstract}

O que aproxima o presente trabalho da investigação realizada pelas autoras citadas é a possibilidade da emoção, que surge a partir das escolhas dos temas de estudo, modificar as relações existentes do grupo de alunos com as propostas dos professores, quando na ampliação de conceitos e abordagem dos conteúdos formais das diferentes disciplinas. E ainda, os dois estudos trazem em comum a análise da forma de aprender cooperativamente, utilizando as tecnologias existentes na escola, para enriquecer e tornar mais agradável o cotidiano em sala de aula. Entretanto, nesta pesquisa, não se observou a utilização da metodologia de Projetos de Aprendizagem (PAs) em sala de aula. Ou seja, as escolhas dos alunos para a escrita de seu TC foram feitas de forma individual (cada aluno escolhia um tema, pesquisava sobre ele e depois construía seu vídeo de apresentação). Todo o planejamento de como seria feito o trabalho e a sua apresentação foi idealizado pelas professoras, a escolha dos alunos esteve relacionada ao tema de pesquisa e na construção da apresentação em vídeo (imagens, músicas). 
Para perceber os enunciados que surgiam a partir dos modos de interação dos jovens, enquanto utilizavam as tecnologias disponíveis no LI e os efeitos de sentido que ressoaram desses enunciados, foram utilizadas as seguintes práticas:

- Observação dos jovens no LI, principalmente quando estiveram pesquisando e elaborando seus vídeos, a fim de visualizar e ouvir a forma como eles interagiam entre si, com os professores responsáveis e com a tecnologia para construção de seus trabalhos, durante os meses de julho a novembro de 2010.

- Realização de conversa informal com alguns destes jovens, para entender como eles chegaram a suas escolhas de temas e conhecer quais suas habilidades para construção de vídeos. As anotações no diário foram feitas durante os encontros no LI enquanto uma das pesquisadoras, professora na escola, auxiliava os estudantes na realização da atividade ou quando alguns estudantes a procuravam no LI para tirar dúvidas ou pedir auxílio sobre o uso do aplicativo WMM.

\section{Relações dialógicas no laboratório de informática.}

Cada turma frequentava o Laboratório de Informática, no mínimo uma vez por semana, por um período de cinquenta minutos. As professoras tinham o hábito de reservar quinze ou dez minutos, ao final do período, para que os alunos navegassem livremente, após a realização da pesquisa.

Nestes encontros observou-se que vários estudantes não lembravam sua senha para acessar o $e$-mail ${ }^{1}$. Era preciso toda semana ajudá-los a recuperar a senha e entrar no ambiente para que eles pudessem editar, enviar e armazenar seus trabalhos. Depois do processo de recuperação de senha, foi necessário anotar a senha destes alunos em uma agenda, pois mesmo anotando em seus cadernos, na aula seguinte, eles não encontravam a anotação, não estavam com o caderno onde haviam anotado ou escreviam alguma coisa errada, um número trocado ou uma letra faltando. Observou-se que isso não ocorria com aqueles alunos que utilizavam MSN e redes sociais ou que, no decorrer do semestre, passaram a fazê-lo nos momentos livres.

Percebeu-se que, para alguns alunos utilizar o e-mail e suas ferramentas, não fazia sentido. Já aqueles estudantes cujo e-mail e senha eram utilizados nos momentos livres, para diversão e interação com amigos (bate papo, blogs pessoais) ou contato social virtual (através do MSN, Orkut, Facebook ou outras redes sociais) não apresentaram dificuldades para memorizar login e senha. O que nos leva a refletir sobre o fato de a aprendizagem estar diretamente relacionada com desejo e necessidade.

A maioria dos estudantes, em suas falas, expressava "gostar de estar" no LI, em contato com o computador e aprendendo a utilizar os recursos disponibilizados para os trabalhos. Abaixo, alguns diálogos de estudantes com uma das pesquisadoras.

Professora: O que vocês estão achando de fazer este trabalho de pesquisa?

Estudante 1:Fazer esse trabalho é bala! Fico esperando chegar o dia de vir pra informática, é tri mexer no computador! E quando termina dá pra ficar livre. (SIC)

Estudante 2: Assim a gente aprende mais que na sala porque a gente pode ver as imagens e ler várias coisas diferentes, e é bom mexer no computador, né? Eu gosto mais do que pesquisar no livro. No livro também não tem um monte de coisa que tem aqui e demora mais. E eu que escolho o que vou pesquisar. Meu trabalho é sobre o meu time...

Estudante 3: Eu vou na Lan House e mexo no computador, mas lá eu só jogo e fico no Orkut, não aprendo a escrever e pesquisar que nem aqui no colégio, é um pouco mais difícil aqui, as vezes é chato também, tem que ler e eu não gosto muito mas é pra gente aprender, pro nosso futuro, pra ter um trabalho bom. Eu quero pesquisar sobre as guerras porque eu acho bem legal. 
Professora: Vocês gostam de vir para cá, fazer a pesquisa aqui no Laboratório de Informática? Por quê?

Estudante 1: Aprender mexer no computador é bom pro nosso futuro, pra qualquer emprego tem que saber mexer no computador, depois eu vou fazer um curso[...]

Estudante 2: Aqui na informática é bom que tem várias professoras pra ajudar a gente. As professoras aqui ficam até mais calmas que na aula. É que aqui não tem bagunça que nem na sala, ninguém fica incomodando e as professoras não se irritam. E depois quem termina pode ficar livre, jogar, ouvir música.

Estudante 3: Escrever no computador é bala, no caderno é frau! Escrever no caderno cansa mais. No computador se a gente escreve errado, daí já aparece e a gente arruma, fica mais certo e mais bonito que no caderno, que tem que ficar apagando e a gente faz até mais rápido. (sic)

É relevante pensar o quanto os professores precisam estar atentos aos enunciados que surgem neste e sobre este espaço da escola. O LI, atualmente, mostra-se como um espaço onde é possível, para o professor, assumir um papel de observador, porque, na maioria do tempo em que está lá, dependendo de sua proposta de trabalho, ele deixa de ser o centro do processo tornando-se um mediador. Por isso é preciso que o professor esteja bem preparado para ocupar este papel de forma responsável, criativa e provocadora.

Para Bakhtin (2006), todos os enunciados são dialógicos no processo de comunicação. Nos enunciados há uma dialogização interna perpassada pelo enunciado de outro e por isso é sempre, também, o enunciado de outro. Nessa perspectiva, todo discurso está atravessado pelo discurso de outro. A produção de sentidos ocorre na interação dialógica, na atitude responsiva ativa que um sujeito assume frente ao enunciado de outro sujeito. $\mathrm{O}$ encontro entre sentidos forma um novo sentido, os sentidos são produzidos durante as relações dialógicas entre os sujeitos.

O espaço do LI pela disposição dos computadores, a proximidade entre os estudantes e os professores que circulam pelo espaço e a possibilidade de trocas constantes de informação propiciam a interação e o diálogo.

Outro exemplo de diálogo, que é interessante destacar:

Estudante 1: Porque tu não vai direto na Wikipédia pra pesquisar? No Google vem muita coisa e a gente perde tempo até achar o que presta.

Estudante 2 : Aonde? (SIC) Não sei o que é? Como é que faz?

Estudante 1: É um site que tem as coisas pra pesquisar. Wikipedia... bota ali, no Google. Aqui, ó, neste quadradinho, olha como escreve. Daí tu já bota o que tu quer e vem um monte de coisa. É mais ligeiro, depois tu só busca as imagens no Google.

O estudante 1 escreve no computador a palavra Wikipedia, na aba do Google, no navegador. Eles encontram através da busca do site Wikipedia o assunto que estavam procurando.

Estudante 2: Bah! Melhor né? Vai mais rápido. Dá pra terminar logo essa parte. Bah, mas é um monte de coisa, vou ter que ler tudo primeiro. Tu já escreveu a primeira parte aquela?

Estudante 1: A introdução já. Eu fiz na aula, fiz no caderno, daí a sora olhou e só depois eu arrumei e botei aqui no computador. Copiei aqui.

Estudante 2: É que eu não vim na aula. Como é que faz mesmo?

Estudante 1: Ah! Não sei, não me lembro, chama a sora. A sora G. ela te explica isso aí. Já to quase terminando o texto aqui. Depois vou entrar num jogo.

Estudante 2: Ah! Não vou fazer isso tudo hoje. Muita coisa.

Estudante 1: Vai só copiando e colando, depois tu resume. Mostra pra ela que tu já fez um pouco.

Estudante 2: É! Já era! (risos)

Estudante 1: É só que depois ela vai ler no e-mail, tu tem que mandar pra ela. (risos)

Estudante 2: Bah! É! Vou dizer que eu não consegui mandar. Que não deu tempo.

Estudante 1: Só que daí tu vai te atrasar. Não vai terminar nunca pra começar o video. Olha a sora ali, te olhando. 
Ao analisar o diálogo acima é possível perceber que para além do objetivo principal do trabalho que é a escolha de um tema e a pesquisa sobre determinado assunto ou conteúdo, os estudantes estão realizando trocas de outros conhecimentos que também são importantes para a realização do trabalho e dos objetivos determinados pelos professores. Há trocas de informações, de recursos e sites que podem ser usados, de combinações de grupo que precisam ser respeitadas. Na medida em que há acolhimento do interesse dos alunos e se possibilita um espaço para trocas entre eles, não um espaço totalmente livre, mas um espaço organizado, com combinações estabelecidas, com objetivos a serem alcançados, com acolhimento dos sentidos instituídos pelos estudantes e da sua produção, para além do certo ou do errado, se estabelece uma relação de confiança entre professores e alunos. Esta relação parece contribuir com a mudança de atitude do aluno, pois, neste caso, ele escolhe realizar o seu trabalho e não abandoná-lo ou trocá-lo simplesmente pelo prazer de jogar livremente, como, a princípio, parecia ser a sua intenção, pois ao ser questionado pelo colega, ele se dirige à professora e pede que ela o auxilie a realizar a introdução que não havia feito na aula que não estava presente.

Segundo Sobral (2007, p.22)

[...] a experiência do mundo humano é sempre mediada pelo agir situado e avaliativo do sujeito, que lhe confere sentido a partir do mundo dado, o mundo como materialidade concreta. Como mostra a obra de Bakhtin, não se trata porém de propor a relatividade dos valores, mas, pelo contrário, o fato de que o valor é sempre valor para sujeitos, entre sujeitos, numa dada situação. Portanto, o agir do sujeito, sem negar a realidade dada do mundo, também o postula ou, no caso do estético, o cria.

O sujeito de Bakhtin é pensado no contexto complexo da ação (vida) e é preciso para conceber este sujeito, considerar o princípio dialógico, mais amplo do agir (viver) que implica interação e percepção da multiplicidade de pensares ou de vozes (polifonia) que estão presentes na ação.

\section{A interação favorecida durante a construção de vídeos para apresentação dos trabalhos de pesquisa.}

É possível observar que a interação e a colaboração ficam favorecidas quando os alunos utilizam os computadores no LI. Os estudantes sentam-se próximos uns aos outros, observam o que o colega ao lado está fazendo e conversam sobre os aplicativos e assuntos que estão estudando. Observou-se, em alguns momentos, que estudantes com menos vivências no manuseio dos computadores e aplicativos ouviam atentamente os colegas com maior vivência e questionavam sobre melhores formas de uso dos aplicativos. Aqueles estudantes que sabiam mais explicavam com paciência aos colegas como fazer para obter um melhor desempenho no manuseio do equipamento e na conclusão das atividades.

Alguns estudantes possuíam um maior conhecimento no uso dos computadores e dos aplicativos do que suas professoras. Neste caso, as professoras podiam aprender com os estudantes e era possível observar uma troca de conhecimentos: o estudante ensinava a professora a utilizar a ferramenta; a professora orientava o estudante sobre a sua pesquisa, sua produção textual, sua ortografia e o ajudava a refletir na escolha das imagens e textos. Esta relação, em nosso entendimento, propicia que o professor dispa-se daquela necessidade de

dizer o tempo todo o que é certo e errado, de determinar como o aluno deve agir. É possível observar o potencial do aluno, as suas diferentes habilidades o que em uma aula tradicional, muitas vezes, não é possível.

A estrutura física ${ }^{2}$ da escola, de modo geral, em sala de aula convencional favorece para que as propostas dos professores sejam de que os alunos realizem suas atividades individualmente, uma mesma atividade é proposta para todos, independente da capacidade, 
do nível de conhecimento de cada um. Por isso, a professora precisa explicar mais, falar mais, e, muitas vezes, o silêncio é pedido constantemente. Sua voz precisa se sobrepor a dos alunos (que devem ouvi-la em silêncio), sob pena de precisar repetir muitas vezes a mesma coisa para que todos a ouçam e compreendam. As tarefas são propostas para que os alunos as realizem, de preferência em silêncio, sem auxílio dos colegas, depois de aprontá-las, haverá a correção da professora e esta correção, na maioria das vezes, acontece para o grande grupo e novamente o silêncio é necessário. Quando há muita diversidade na turma, é quase impossível atender aos alunos com mais dificuldade/defasagem.

No LI, durante as atividades relatadas havia a presença de mais de uma professora ${ }^{3}$, às vezes, três professoras, incluindo a do LI, acompanhavam as turmas. Este apoio, de mais de uma profissional, facilitava o atendimento para aqueles estudantes que necessitavam de intervenções e auxílio para aqueles que demoravam mais para compreender e realizar a tarefa (muitos alunos faltam às aulas, chegam atrasados ou distraem-se enquanto a professora explica a tarefa para o grande grupo).

A concepção piagetiana da natureza do conhecimento e suas hipóteses sobre o desenvolvimento intelectual são tomadas neste trabalho para entender como as interações no espaço do LI, com o computador e os aplicativos disponibilizados ali, bem como, o acolhimento das escolhas dos estudantes sobre o que aprender pode facilitar a reflexão do professor sobre os conteúdos e as estratégias utilizadas para o desenvolvimento de suas aulas.

Ao analisar as situações ocorridas no LI, nos reportamos aos estudos de Piaget, que considera que as condutas cognitivas se manifestam por seu poder de assimilação e de acomodação. A assimilação é um processo de integração de objetos novos a estruturas preliminares e elaboração de estruturas novas pelo sujeito agindo em interação com o meio. A acomodação ocorre quando o sujeito encontra um novo problema e tenta, através da modificação de seu comportamento, resolvê-lo. Os esquemas já existentes são assim modificados pela adaptação aos novos aspectos do problema emergente. Os dois processos se complementam mutuamente, são elementos do processo de abordagem ativa do ser humano.

A teoria da equilibração, de uma maneira geral, trata dos esforços do sistema cognitivo na busca de um ponto de equilíbrio (jamais alcançado) entre os dois esquemas (assimilação e acomodação) e é necessária, como um mecanismo autorregulador, assegurando que os processos relacionais de interação sejam contínuos e permanentes, enquanto houver vida. Compreender esta teoria é importante para entender o paradigma adotado para a proposta desta atividade de escolha de temas e criação de vídeos pelos estudantes no LI.

Ao propor aos estudantes a construção de vídeos para apresentação de seu TC, o grupo de professoras provocou uma mudança de estratégia, ou seja, eles passaram da digitação de um trabalho escolar convencional ou do plágio de páginas da internet, avaliado muitas vezes apenas pelo aspecto gráfico caprichado e pela extensão de um texto, nem sempre autoral, para outro tipo de construção. Nesta outra proposta, o desequilíbrio necessário para que ocorra a aprendizagem conforme a estrutura da equilibração passou a ser provocado constantemente através das intervenções dos professores, dos próprios colegas, e na utilização dos equipamentos, quando em interação.

Neste tipo de proposta, mesmo que os alunos estivessem utilizando figuras, músicas e textos de outros autores, eles precisariam, através de associações e de síntese, coordenar as imagens e produzir efeitos condizentes com aquilo que queriam mostrar. Além disso, era preciso, durante a produção dos vídeos, relacionar vários elementos, conferir a estética e a correção do seu trabalho, observar o impacto que a imagem e a música causariam nos espectadores e entender (minimamente) do assunto que estavam apresentando.

Para a conclusão do trabalho, precisariam dominar o aplicativo, aprender técnicas de inserção de imagem e texto, prever o tempo adequado para a(s) música(s) escolhida(s) e aprender que a resolução de imagem, a utilização de cores agradáveis, a adequação e a 
correção dos textos e músicas são recursos importantes para a produção de um trabalho atrativo e interessante. É importante lembrar que algumas das professoras diretamente envolvidas no trabalho não dominavam, a princípio, o aplicativo WMM e, tampouco, conheciam o site utilizado para fazer downloads de músicas, o 4 shared $^{4}$. Elas aprenderam a utilizar os recursos juntamente com os estudantes, nas trocas, na experimentação, através dos erros e acertos e interagindo com os recursos.

A concepção construtivista acerca da aprendizagem considera que o conhecimento se consolida a partir de autorregulações ${ }^{5}$. O erro deixa de ter caráter inibidor e passa a ser construtivo para a aprendizagem, mais importante do que o acerto imediato é o processo de elaboração, de construção.

A situação descrita a seguir, envolve duas estudantes e uma professora: G. já havia concluído o seu vídeo, a aluna já sabia construir vídeos e blogs. Ela concluiu o trabalho bem antes dos outros colegas e, por iniciativa própria, criou e passou a alimentar um blog sobre o seu tema de pesquisa. Normalmente, ela auxiliava os colegas a construírem seus vídeos e era bastante solicitada, comunicava-se bem com todos e se mostrava interessada em ajudar. Em uma manhã, uma das professoras solicitou a ajuda de G..

A seguir, o diálogo entre elas.

Professora 1: G. Tu podes auxiliar a P. aqui com o vídeo dela, eu vi que tu inseriste um texto no clipe, como tu fizeste isso? Explica aqui pra ela, eu quero ver como é para aprender.

Aluna G.: Ãh?! Tá, sora, já to indo aí. É tipo... eu fiz uma legenda, sora!

Professora 1: Sim, mas queremos saber como se faz.

$[\ldots]$

Aluna G.: Tá sora. Eu vou te ajudar agora. (SIC)

A aluna P., com o auxílio de G., insere todos os textos no formato de legenda. Depois que havia inserido todos os textos, ela coloca as transições entre os clipes ( cada parte do vídeo). As transições dão movimentos às imagens estáticas, há vários efeitos de transição que podem ser inseridos. Porém, ao inserir as transições, todas as legendas saíram do lugar, pois as transições modificaram o tempo do clipe. A aluna P. chama, então, a professora para ver o que houve, pois ela e G. não entenderam por que o problema ocorria. A professora 1, também não entende o que pode ter acontecido e pede que P. refaça as legendas, ela acha que a menina colocou as legendas nos clipes errados. P. concorda e refaz todas as legendas.

Posteriormente a professora seguiu explicando para outros estudantes como criar as legendas, mas ela não se deu conta de lembrá-los que era necessário inserir as transições entre os clipes antes de escrever o texto sobre eles e, por isso, outros alunos começaram a ter o mesmo problema da aluna $\mathrm{P}$., ou seja, precisaram refazer tudo, pois as legendas saíram do clipe desejado e passaram para o posterior. A professora dirigiu-se para G. e perguntou se ela sabia por que isso ocorrera. G. também não entendera o motivo do erro, pois quando criou o seu vídeo não observou este problema. Elas passaram a cogitar que poderia ser um problema no programa WMM e solicitaram ajuda a professora do LI, que no momento, sem observar, não soube explicar o que podia estar acontecendo.

Intrigadas com o erro, as duas professoras e G. passaram a observar um dos alunos que estava construindo o seu vídeo e perceberam que ele colocara transições entre os clipes após a escrita dos textos e que por isso houve um deslocamento do texto de um clipe para o outro. Depois de descobrirem a causa do deslocamento, foi explicado, pela professora do LI, que eles poderiam acessar a linha de tempo dos clipes e recolocar as legendas no lugar certo (clicando e arrastando), não seria necessário reescrever todos os textos de novo.

Durante a oficina preparada para explicar o uso do WMM, fora falado e oferecido um texto explicativo para os alunos, onde dizia que era preciso primeiro colocar as transições para depois acrescentar os textos, o que facilitaria, caso algum dos alunos utilizasse as 
sobreposições (texto sobre a imagem). Informalmente, enquanto conversava com a professora do LI um dos alunos implicados falou que não se lembrava dessa fala durante a oficina, mas que agora havia entendido o porquê de se fazer seguindo os passos, pois seria mais difícil ocorrer este erro, outro aluno disse que o erro o fez aprender a consertar usando a linha de tempo, que até então não havia acessado no programa, outro disse que já tinha visto a linha do tempo, mas que não tinha entendido o porquê daquele formato. Outro aluno concluiu, a partir do manuseio do programa, que mesmo sendo possível corrigir sem ter que fazer toda a parte escrita de novo, arrastando as sobreposições e soltando sobre o clipe certo, era mais fácil e rápido colocar as transições do que arrastar e soltar, pois às vezes demorava até acertar o local da legenda desta forma e o programa "trancou" algumas vezes.

Pode-se observar que ocorreu uma aprendizagem a partir do erro, da observação e da experimentação. Neste caso, houve uma assimilação quando os estudantes aprenderam a utilizar as legendas e a linha do tempo e uma acomodação quando os estudantes entenderam que era mais fácil colocar primeiro as transições do que arrastar e soltar as legendas nos clipes utilizando a linha de tempo. Apesar de ter sido dito, durante a oficina, que logo após inserir as imagens, deveriam colocar as transições, esta aprendizagem só ocorreu após os estudantes enfrentarem um problema durante a execução do seu projeto de vídeo, ou seja, os alunos precisaram encontrar um problema e através da ação, do seu comportamento em interação com o objeto, resolvê-lo assimilando novas situações.

Talvez outros alunos que não enfrentaram o mesmo problema só venham a aprender efetivamente quando, a partir do erro, tiverem que descobrir o que ocorreu e precisarem corrigir o erro, em sua prática, na utilização do aplicativo.

Piaget (1978) diz que a tomada de consciência pode ocorrer através de inadaptações nas ações, porém ele enfatiza que ocorreria mesmo sem as inadaptações. Este processo exige coordenações e transformações contínuas que dão origem a diferentes níveis de consciência e integração dos esquemas, que são resultados da forma como as regulações apresentam-se em cada estágio de desenvolvimento. Nem todo nível de consciência implica conceituação, esta depende das integrações que são estabelecidas entre o conhecimento novo e o anterior.

É interessante observar um trabalho onde a aprendizagem ocorre efetivamente a partir dos erros e acertos dos sujeitos e de como a ação sobre o objeto de aprendizagem, neste caso o aplicativo WMM, pode levá-los a inferências de aprendizagem, as quais, como observado, estão diretamente relacionadas ao sentido.

Neste momento, parece válido salientar, para fins desta pesquisa, que muitas vezes os estudantes vivenciam momentos de aprendizagem, que não são possíveis de observar ao lermos registros de planejamento dos professores. O momento em que a aprendizagem ocorre, em muitas ocasiões, não se dá no momento esperado, a partir do que foi proposto como uma ação específica previsível e especificada registrada no plano de aula. A aprendizagem pode ocorrer do inusitado, no encontro de um problema, na relação de sentido, numa particularidade. As circunstâncias são singulares e envolvem cada sujeito, seus desejos, seus interesses, suas necessidades e, por isso, a afetividade está também implicada nesse processo. E o professor precisa estar preparado para enfrentar essas situações e explorar a potencialidade das invenções.

\section{Considerações Finais}

Este trabalho procurou descrever uma situação de aprendizagem ocorrida no LI de uma escola pública, localizada na periferia da cidade de Porto Alegre, utilizando o software WMM para edição de filmes e analisar como ocorreram os processos de interação, relações dialógicas e produção de sentidos nesta experiência, a partir das escolhas dos estudantes e do planejamento dos professores. Verificou-se que a proposta de ensino tornou-se atraente para 
os estudantes ao possibilitar que eles fizessem escolhas sobre o que desejariam pesquisar e a partir desse trabalho pudessem criar um filme, utilizando os recursos disponíveis no LI, para apresentar aos demais estudantes e também seus familiares e professores, em momento especialmente organizado para isso.

O LI poderia ser só mais um espaço da escola, onde os professores levariam os estudantes na intenção de proporcionar, com o acesso aos recursos lá disponibilizados, situações de aprendizagem que poderiam ou não tocá-los. Entretanto, o desejo dos estudantes de criar, utilizando os computadores e as TIC, o tornou um ambiente extremamente favorável à aprendizagem, não só pelos recursos de mídia disponibilizados, mas também pela forma como a interação e as trocas ficaram favorecidas pela organização física do espaço, que permite a aproximação entre os estudantes e a circulação das professoras entre eles. Notou-se que as professoras tornaram-se mais flexíveis às trocas e aos diálogos entre os estudantes e puderam exercer o papel de mediadoras favorecendo as relações dialógicas, a interação e a troca de saberes em diferentes grupos. Observou-se no LI que, a partir do acolhimento de suas escolhas, os estudantes puderam modificar relações de aprendizagem com a escrita, com a leitura, com outros conceitos propostos ou não pelos professores, e, principalmente, com a tomada de decisão sobre a aprendizagem destes conceitos.

Os sentidos de dever, respeito às combinações de grupo, apresentação de resultados das pesquisas, atenção às particularidades dos equipamentos do LI, o porquê de algumas situações precisarem ser observadas na hora de salvar os trabalhos, a correção da escrita, a resolução adequada da imagem, o impacto visual e da música no espectador do vídeo produzido, não podem ser desprezados, pois permitem que aconteça para além do desenvolvimento cognitivo, o desenvolvimento psíquico e a produção de subjetividade dos jovens.

Os resultados finais deste trabalho apontam para a abundância de possibilidades, que o acolhimento pelos professores da escolha dos estudantes (sobre o que aprender) proporciona. O mais significativo nessa situação observada, pode-se dizer, é a capacidade que precisamos desenvolver, como educadores, de ouvir o outro, estar disponível para entender o que lhe aflige, quais são suas necessidades. É ainda importante observar, quando se pretende utilizar as novas tecnologias na escola, que incluir digitalmente, não se resume apenas ao acesso às mídias, ao domínio dos recursos, o projeto de inclusão deve valorizar o efetivo exercício de autoria, conferindo ao sujeito o seu lugar, sua posição discursiva.

É importante pensar sobre o quanto o espaço de planejamento dos professores (esse tempo que escola disponibiliza aos educadores para que organizem seus objetivos, suas estratégias de ensino e para que definam recursos que serão utilizados em suas aulas) precisa privilegiar as escolhas dos estudantes, a fim de que propostas de aprendizagem de conteúdos e temas não resultem em algo sem sentido. O sentido, para Bakhtin, é tudo o que precisa de resposta. Segundo Bakhtin (2006), o sentido sempre responde a uma pergunta e aquilo que responde a nada nos soa como algo insensato.

Ao acolher as escolhas, nem tudo poderá ser pré-determinado, é preciso que haja sempre espaço para replanejar, refletir, reconstruir, reorganizar. O inusitado, não presente no planejamento, poderá ser motivo de angústia, mas é certeza de questionamentos, de respostas não previstas, que enriquecem a produção de sentidos e favorecem a cooperação e a troca.

Para finalizar, desejamos que este trabalho possa despertar outros questionamentos, produzir novos sentidos e estimular olhares diferentes que resultem em benefícios para a formação dos professores e sua atuação nas escolas, favorecendo trocas e aprendizagens. 


\section{Notas}

${ }^{1}$ Os e-mails haviam sido criados no início do projeto para a maioria dos alunos que ainda não possuíam. Observou-se que somente tinham e-mail alunos que costumavam utilizar redes sociais, que era a minoria.

${ }^{2}$ Salas pequenas para o número de estudantes, com as mesas viradas para o quadro, onde os alunos, em geral ficam sentados sozinhos um atrás do outro. Com poucos recursos audiovisuais, sem internet, sem computadores.

${ }^{3} \mathrm{Na}$ escola observada, em algumas turmas, há um projeto intitulado Docência Compartilhada, onde além da professora especialista há uma pedagoga, que acompanha as aulas para auxiliar alunos com deficiência ou déficit de aprendizagem.

${ }^{4} \mathrm{O}$ site 4shared é um site de armazenamento virtual de arquivos. É gratuito e pode ser usado por qualquer pessoa com uma conta de e-mail (é preciso fazer um cadastro). Neste site é possível postar qualquer tipo de arquivo e deixar a disposição para que qualquer outro usuário da Internet possa baixá-lo. É importante lembrar que essas possibilidades também podem despertar uma discussão sobre direitos autorais na internet. Disponível em: http://www.4shared.com .

${ }^{5}$ Segundo Piaget (2007), o processo de regulação ocorre quando uma ação é executada, mas não atinge seu objetivo plenamente. O agente deve determinar o tipo de correção a fazer na ação e executá-la novamente. A partir desta nova execução poderá avaliar se sua regulação aumentou ou diminuiu o erro. A regulação não consiste em simplesmente repetir a ação, é necessário modificar a ação antes de tentar novamente.

\section{Referências}

BAKHTIN, Mikhail. Estética da criação verbal. São Paulo, Martins Fontes, 2006.

; VOLOSHINOV, Valentin. Discurso na Vida e Discurso na Arte (sobre poética

sociológica). Disponível em: <http://www.fflch.usp.br/dl/noticias/downloads/ Curso_Bakhtin2008_Profa.\%20MaCristina_Sampaio/ARTIGO_VOLOSH_BAKHTIN_DISC URSO_VIDA_ARTE.pdf $>$. Acesso em 11 set.2011.

CORTE REAL, Luciane Magalhães; MARASCHIN, Cleci; AXT, Margareth. Projetos de Aprendizagem e Tecnologias Digitais: Uma experiência promovendo transformações na Convivência na Escola. Disponível em http://www.cinted.ufrgs.br/ciclo9/artigos/ 9cLuciane.pdf. Acesso em 11 out. 2011.

INHELDER, Bärbel, BOVET, Magali; SINCLAIR, Hermine. Aprendizagem e Estruturas do Conhecimento. São Paulo: Saraiva, 1977.

PIAGET, Jean. A equilibração das estruturas cognitivas: problema central do desenvolvimento. Rio de Janeiro: Zahar, 1976.

A tomada de consciência. São Paulo: Melhoramentos/Edusp, 1978.

Epistemologia Genética. São Paulo: Martins Fontes, 2007.

Seis Estudos de Psicologia. Rio de Janeiro: Forense Universitária, 2010.

SOBRAL, Adail. Ato/Atividade e evento. In: Brait Beth. Bakhtin Conceitos-Chave. São Paulo: Contexto, 2007. p.11-36.

. Ético e estético Na vida, na arte e na pesquisa em Ciências Humanas. In: Brait Beth.

Bakhtin Conceitos-Chave. São Paulo: Contexto, 2007. p.103-121. 